\title{
Pediatric motor vehicle related injuries in the Navajo Nation: the impact of the 1988 child occupant restraint laws
}

\author{
K J Phelan, J Khoury, D C Grossman, D Hu, L J D Wallace, N Bill, H Kalkwarf
}

See end of article for authors' affiliations

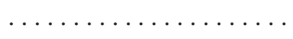

Correspondence to: Dr Kieran J Phelan, Assistant Professor, Pediatrics, Divisions of Clinical Effectiveness and General and Community Pediatrics, Cincinnati Children's Hospital Medical Center, TCHRF 7548, 3333 Burnet Avenue, Cincinnati, $\mathrm{OH}$ 45229-3039, USA

kj.phelan@chmcc.org
Background: Navajo motor vehicle mortality is the highest among the 12 Indian Health Service (IHS) administrative areas. In July 1988, the Navajo Nation enacted a primary enforcement safety belt use and a child restraint law.

Objective: Assess the impact of the laws on the rate and severity of pediatric (0-19 years) motor vehicle injury resulting in hospitalizations in the Navajo Nation.

Methods: Hospitalizations associated with motor vehicle related injury discharges were identified by International Classification of Diseases, 9th revision, CM E codes, 810-825 $(.0, .1)$ from the Navajo IHS hospital discharge database. Age specific rates for the period before the law, 1983-88, were compared with those after enactment and enforcement, 1991-95. Severity of injury, measured by the abbreviated injury scale (AIS) score and new injury severity score (NISS), was determined with ICDMAP-90 software. Wilcoxon rank sum and $\chi^{2}$ tests were used for analysis.

Results: Discharge rates (SE) for motor vehicle injury (per 100 000) decreased significantly in all age groups: 0-4 years $(62(7)$ to $28(4)), 5-11$ years $(55.3(6)$ to $26(4))$, and 15-19 years (139 (14) to 68 (7)); $p=0.0001$. In children 0-4 years, the median AIS score decreased from $1.5(1,3)(25$ th, 75 th centile) to $1(1,2), p=0.06$, and the median NISS decreased from $3.5(1,9)$ to $2(1,5), p=0.07$. The proportion of children with NISS scores $>4$ decreased significantly for the $0-4$ year age group $(p=0.03)$.

Conclusions: Concurrent with enactment of the Navajo Nation occupant and child restraint laws there was a reduction in the rate of motor vehicle related hospital discharges for children. Severity of injury declined in very young Navajo children. The effect of enactment and enforcement of this Native American child occupant restraint law may serve as an example of an effective injury control effort directed at Native American children.
M otor vehicle crash related injury is the leading cause of death in children in the US after the first year of life. ${ }^{1-3}$ As of 1995, all states had enacted some type of child occupant restraint law. Only 19 states have currently passed primary enforcement seat belt laws, allowing police to stop vehicles solely for occupant restraint law violations. ${ }^{4}$ Most Native American tribes in the US, with few exceptions, are viewed as sovereign nations not subject to the traffic laws (and other civil laws) of the surrounding state(s). ${ }^{5}$

The mortality associated with motor vehicle crashes in the US is highest in counties of low population density and inversely correlated with per capita income. This may be due to differences in road characteristics, travel speeds, seat belt use, types of vehicles, and availability of emergency care. ${ }^{6}$ Most Native American reservations are located in rural areas, and Native Americans reside in relative poverty compared with US whites. ${ }^{7}$ The rural environment and relative poverty that many Navajo children live in compared with other US children may place them at particular risk for motor vehicle related morbidity and mortality.

Grossman et al examined differences in risk factors for motor vehicle crashes between rural and urban American Indians and between rural American Indian and non-Native American drivers. These investigators found that rural Native American occupants who did not use safety belt restraints had over a twofold higher risk of injury or death compared with those with seat belts. ${ }^{8}$ These data were not analyzed with respect to the pediatric age range. Unrestrained children are more likely to be severely injured, hospitalized, and to remain impaired upon discharge.'
In 1983, the age adjusted motor vehicle related death rate for Navajos of all ages was 57.0 per 100000 compared with 19.0 per 100000 in the white population. ${ }^{10}{ }^{11}$ The Navajo motor vehicle related death rate ranked first among the 12 Indian Health Service (IHS) geographic areas. ${ }^{71}$ In July, 1988 the Navajo Nation enacted a primary enforcement safety belt use law and a child restraint law. Early assessment of the efficacy of these occupant restraint laws revealed a dramatic effect on seat belt usage and hospitalization rates for adult Navajos for the immediate three years after enforcement. ${ }^{12}$ The possible effects of the law on pediatric morbidity and mortality were not assessed.

The objective of this study was to assess the impact of the 1988 Navajo occupant restraint and child restraint seat belt laws on the incidence of pediatric (0-19 years) motor vehicle crash related hospitalizations and severity of injuries. This ecological study sought to examine hospitalization rates and injury severity for two periods before and after enactment and enforcement of the 1988 Navajo laws. Specifically, two hypotheses were tested:

(1) The 1988 Navajo occupant restraint laws reduced the rate of pediatric motor vehicle crash related injuries discharged from Navajo Area IHS hospitals in 1991-95 compared with 1983-88.

Abbreviations: AIS, abbreviated injury scale; ICD9, International Classification of Diseases, 9th revision; IHS, Indian Health Service; NISS, new injury severity score 
Table 1 Demographic characteristics of children $<20$ years discharged for motor vehicle related injury (E810-825, .0,.1) from Navajo IHS hospitals, 1983-95

\begin{tabular}{llll}
\hline & $\begin{array}{l}\text { Pre-laws } \\
1983-88\end{array}$ & $\begin{array}{l}\text { Post-laws } \\
1991-95\end{array}$ & Total 1983-95 \\
\hline Number discharged & 413 & 315 & 866 \\
Age in years (mean) & 11.5 & 11.6 & $11.3($ range 0-19 years) \\
Male (\%) & $219(53)$ & $168(53)$ & $468(54)$ \\
Driver (\%) & $79(19)$ & $68(22)$ & $174(20)$ \\
Passenger (\%) & $334(81)$ & $247(78)$ & $691(80)$ \\
Alcohol related (\%) & $26(6.3)$ & $28(8.9)$ & $66(7.6)$ (mean age 17 years) \\
Length of stay (median days) & 2 & 2 & 2 (range 0-103 days) \\
\hline
\end{tabular}

(2) The severity of injury in Navajo children due to motor vehicle crashes decreased in association with enactment and enforcement of a child occupant restraint and seat belt laws. We also examined demographic characteristics and seasonal variations of motor vehicle injury related hospitalizations for children from Navajo Area IHS facilities.

\section{METHODS}

\section{Data source}

Data from the IHS hospital discharge data system was utilized for these analyses (IHS Headquarters, Rockville, MD). This dataset includes discharges from both tribal and contract IHS hospitals for eligible individuals who reside in one of the 12 regional service areas of the IHS. Discharge records included three International Classification of Diseases, 9th revision (ICD9)CM) mechanism of injury codes (or "E codes") and up to six ICD9-CM nature of injury codes (or "N codes"), date of admission and discharge, service unit, demographics including tribal affiliation and state, county, and community of residence codes. Navajo children discharged from Navajo Area IHS inpatient and contract health facilities who were less than 20 years with ICD9-CM external cause of injury codes in the range E810-E825 (.0,.1), "motor vehicle related injury, occupant or driver", were included. The IHS hospital discharge records have been shown to be greater than $80 \%$ accurate in assignment of external cause group. ${ }^{13}$

Hospital discharges were included for the years 1983 through 1995. Data from outpatient visits were not available in electronic format for the entire study period and were therefore not included. Individual discharge records were used as numerator data to develop rates and proportions. IHS service population estimates, which are census based population specific projections, for the Navajo Nation were used to develop denominators for rates and proportions. ${ }^{7}{ }^{14}$ None of the various community hospitals, pediatric intensive care units, and trauma centers in the states and counties surrounding the Navajo Nation had complete E coded data for Navajo patients transferred to their facilities from 1983 through 1995. Approval of the study protocol was obtained from a tribal chapter house, the Navajo Area Health Board, the Navajo Area Health Research Review Board, and the Cincinnati Children's Hospital Medical Center Institutional Review Board.

The IHS Navajo Nation hospital discharge dataset contained 1575 records for hospital discharges for all motor vehicle related injury E810-825 (.0-.9) from the Navajo Area IHS facilities for people less than 20 years of age between the years 1983 to 1995 . There were 866 records with ICD9-CM E codes in the range $810-825(.0, .1)$, "motor vehicle related injury, occupant or driver". In order to reduce the chance of inflating estimates by counting multiple admissions for the same injury event, we assessed the records for readmissions. A readmission was defined as a discharge for which the month of discharge, date of birth, sex, state, county, community of residence were identical. Only 18 out of $866(1.8 \%)$ were readmissions.

\section{Injury severity}

Injury severity was measured by determining the abbreviated injury scale (AIS) score and the new injury severity score (NISS). The AIS and NISS were determined from the ICD9-CM $\mathrm{N}$ codes in the records using ICDMAP-90 software. ${ }^{15}{ }^{16}$ The scores developed by this software result in conservative estimates of injury severity. ${ }^{17}$ The mapping software and the injury severity scores it generates have been validated in pediatric trauma datasets. ${ }^{18}$ Due to their commonly skewed distributions, these severity scores have been shown to be most appropriate when used as categorical variables. ${ }^{19}$ The mapping software could not apply a severity score to 87 out of the 866 (or 10\%) of records due to inadequate or non-specific information on the nature of the injuries. The proportion of imputed values for 1983-88 and 1991-95 were not significantly different (12\% v 8\% respectively, $\mathrm{p}=0.092$ ). A conservative strategy was used and severity scores were assigned a " 0 " or " 1 " (no or mild injury) to those records that did not have assignable scores to minimize the potential bias associated with missing data. Analysis of severity scores with and without missing values did not alter the conclusions of this study.

\section{Statistical analysis}

In order to examine the effect of the law on children injured and hospitalized from motor vehicle related trauma, two periods before and after enactment and enforcement (1983-88 and 1991-95) of the Navajo child restraint and occupant restraint laws were examined. Enactment of the laws occurred in 1988 and enforcement in 1990; therefore, a period before existence of any such laws (1983-88) and a period after enactment with primary enforcement were compared (199195). In addition, discharge rates and associated demographics for the 13 year period of study (1983-95) were examined. In order to examine possible effects on more severe injuries, the proportion of injuries by age group with AIS scores greater than 1 and NISS greater than 4 were examined. These thresholds (AIS > 1 and NISS >4) constitute "moderate-to-severe" injuries and have been used by other investigators to categorize more severe injuries in children. ${ }^{20}{ }^{21}$ Rates and proportions were compared using the Pearson $\chi^{2}$ statistic, and injury severity scores were analyzed using the Wilcoxon rank sum test. ${ }^{22}$ The population studied was split into age groupings for comparisons to reflect the stipulations of the 1988 Navajo occupant restraint laws.

\section{RESULTS}

There were a total of 866 discharges from Navajo IHS facilities for children less than 20 years with motor vehicle related injuries (occupant or driver) over the 13 year period of study. The mean age of Navajo children discharged from Navajo IHS hospitals was 11.3 years (table 1). Over half of the children discharged were male. More than three quarters of Navajo children injured and hospitalized were passengers in motor vehicles. Alcohol was involved in fewer than $8 \%$ of motor 
Table 2 Mean annual hospital discharge rates* for motor vehicle related injury (E810-825, .0,.1)

\begin{tabular}{llll}
\hline Age (years) & $\begin{array}{l}\text { Pre-laws } \\
1983-88\end{array}$ & $\begin{array}{l}\text { Post-laws } \\
1991-95\end{array}$ & $\mathrm{p}$ Value \\
\hline $0-4$ & 62.2 & 28.0 & 0.0001 \\
$5-11$ & 55.3 & 26.0 & 0.0001 \\
$12-19$ & 139.0 & 68.0 & 0.0001 \\
All $<20$ & 81.7 & 41.3 & 0.0001 \\
\hline
\end{tabular}

*Per 100000 persons, Navajo Area IHS hospitals.

Table 4 Proportion of discharges with

"moderate-to-severe" injuries (NISS >4) before and after enforcement

\begin{tabular}{lrrl}
\hline Age (years) & $\begin{array}{l}\text { No }(\%) \\
1983-88\end{array}$ & $\begin{array}{l}\text { No }(\%) \\
1991-95\end{array}$ & $\mathrm{p}$ Value \\
\hline $0-4$ & $37(43.0)$ & $16(25.8)$ & 0.03 \\
$5-11$ & $43(46.2)$ & $28(40.6)$ & NS \\
$12-19$ & $117(50.0)$ & $91(49.5)$ & NS \\
All $<20$ & $197(47.7)$ & $135(47.9)$ & NS \\
\hline
\end{tabular}

vehicle related injury discharges, and the mean age of patients discharged for motor vehicle related injuries where alcohol exposure was recorded was 17 years. The demographic characteristics of the two cohorts of Navajo children did not change significantly over the period of study.

The hospital discharge rates for Navajo children decreased significantly in the five year period examined after the enactment of the occupant restraint law compared to that before enactment and enforcement (table 2). The discharge rates decreased by more than $50 \%$ for each age group $(\mathrm{p}<0.0001)$.

The distribution of severity scores was highly skewed. The severity of injury for children discharged from Navajo IHS facilities was relatively low overall and increased slightly with increasing age. The median severity of injury, as measured by AIS scores and NISS, for discharged Navajo children of any age group did not change significantly in the five year period after the law compared with the period before enactment (table 3, p=0.77). There was a decreasing trend toward reduced severity in the 0-4 year age group for both AIS score and NISS but this did not reach statistical significance (table $3, p=0.06$ and $p=0.07$ respectively). There was a significant decrease in the proportion of 0-4 year old Navajo children discharged with more severe injuries (NISS $>4$ ) after institution of the law (table $4, p=0.03$ ). There was no significant change in the proportion of records with AIS scores greater than 1 between the two time periods. None of the older age groups experienced a significant decline in the proportion of severely injured children discharged in the five year period after enactment and enforcement.

In order to examine whether road conditions may have affected restraint use and subsequent discharge rates for
Table 5 Seasonal IHS hospital discharge rates (per 100000 ) for Navajo children $<20$ years before and after enforcement

\begin{tabular}{llcl}
\hline Season & $1983-88$ & $1991-95$ & $\mathrm{p}$ Value \\
\hline Spring & 25.3 & 11.8 & 0.001 \\
Summer & 26.1 & 14.6 & 0.001 \\
Fall & 18.6 & 6.6 & 0.001 \\
Winter & 17.1 & 8.4 & 0.001 \\
\hline
\end{tabular}

injured children, the season of discharge was examined. The discharge rates declined in each season by more than $50 \%$ for all discharged children less than 20 years (table $5, \mathrm{p}=0.001$ ).

\section{DISCUSSION}

The hospital discharge rates for Navajo children injured in motor vehicle crashes decreased significantly in association with the enactment and enforcement of a child occupant restraint law and seat belt law. In addition, the proportion of children discharged with more severe injuries (NISS $>4$ ) significantly decreased for Navajo children less than 5 years of age after enforcement of the child restraint laws. This is the first study to examine the effect of occupant restraint laws on motor vehicle injury in Native American children. The beneficial effects of child occupant restraint shown in Navajo children in this study may be replicable in other Native American tribes currently without child occupant restraint laws. ${ }^{23}$ In a 1999 survey of tribal traffic safety laws conducted by the IHS and the National Highway Traffic Safety Administration, fewer than half of tribes surveyed (30 out of 86 reporting) had enacted a primary enforcement seat belt law.

In association with enactment and enforcement of the 1988 laws, the Navajo IHS instituted area-wide campaigns, which included education on occupant restraint and car seat promotion, rentals, and giveaways. In 1992 the Centers for Disease Control, in collaboration with the Navajo Area Office of Environmental Health and Navajo Department of Highway Safety, published data showing an increase in safety belt use from $14 \%$ to $60 \%$ by front seat occupants for periods before and after the 1988 laws. These data were compiled from observational surveys conducted on front seat occupants at sites throughout the Navajo Nation by IHS staff from 1985 through the present. ${ }^{12}$ The failure to reduce injury severity in the older age groups may reflect a lack of restraint usage in the older age groups, inappropriate restraint, or engineering difficulties in occupant restraint for children over 4 years. ${ }^{24} 25$ Pick-up trucks are essential transportation vehicles for people living in rural areas of the US such as the Navajo Reservation and Trust Lands. Children should not be transported in pick-up truck beds until restraint is designed to prevent their ejection and to effectively protect them from the transmission of energy involving crashes with these vehicles. ${ }^{26}{ }^{27}$ Even with passage of a primary enforcement seat belt law, appropriate child occupant restraint remains a challenge. Observational

Table 3 Number of discharges and median injury severity (25th, 75th centiles) for Navajo children by age group, 1983-95

\begin{tabular}{llllllll}
\hline & \multicolumn{2}{l}{$1983-88$} & & & \multicolumn{2}{l}{$1991-95^{*}$} & \\
\cline { 2 - 3 } Age (years) & No & AIS & NISS & & No & AIS & NISS \\
\hline $0-4$ & 86 & $1.5(1,3)$ & $3.5(1,9)$ & 62 & $1(1,2)$ & $2(1,5)$ \\
$5-11$ & 93 & $2(1,3)$ & $4(1,9)$ & & 69 & $2(1,2)$ & $4(1,8)$ \\
$12-19$ & 234 & $2(1,2)$ & $4.5(2,9)$ & & 184 & $2(1,3)$ & $4(2,9)$ \\
\hline
\end{tabular}

AIS=abbreviated injury scale score; NISS=new injury severity score.

*No significant difference between time periods for any age group. 
data from the Navajo Area IHS, Department of Environmental Health and Injury Prevention Program show that about $68 \%$ of adults utilize some form of occupant restraint. However, rates of child restraint appear to be much lower (unpublished data, Navajo Area Injury Prevention Program).

The 1988 Navajo law was associated with a $28 \%$ decrease in motor vehicle injury hospitalization for all Navajos two years after enactment. ${ }^{12}$ The effects of the laws on the Navajo pediatric population were found to be of greater magnitude in this study. Occupant restraint laws have been associated with appropriate behavioral change in motor vehicle drivers and passengers. ${ }^{28}{ }^{29}$ Laws specific to the childhood ages have been associated with a more immediate effect on child occupant restraint..$^{30}$ Primary enforcement laws have been shown to have a greater effect on reducing mortality risk. ${ }^{31}$ Use of occupant restraint has been associated with a reduction in childhood injury, hospitalization, and mortality in several other studies. ${ }^{32-34}$

Reductions in pediatric injury associated with Native American occupant restraint laws have not been reported before this investigation. Quinlan et al examined hospital discharge rates over an 11 year period, 1981-92, for motor vehicle injury mechanisms in Native Americans of all ages and found a $65 \%$ reduction in rates of discharge for youth up to 24 years using data from 11 out of 12 US tribes. Navajo Nation youth under 24 years, however, only experienced a $30 \%$ decline in this study. ${ }^{35}$ The authors, however, did not relate their findings to any specific occupant restraint laws. Furthermore, some of the IHS areas included in the Quinlan study were urban settings with modern road traffic environments and emergency medical systems. The present study, in contrast, examined age groupings prescribed in the 1988 Navajo laws (0-4 child safety seat, 5-11 child occupant restraint, 12-19 restrained front seat occupants) over a 13 year period (198395).

There are a number of limitations to ecological designs used to evaluate laws intended to reduce injury morbidity and mortality. ${ }^{36}$ It is difficult to account for secular trends with such designs. All 50 states now have some form of occupant protection law. There was a $24 \%$ decrease in pediatric motor vehicle occupant deaths from 1978 through 1991 across the US in parallel with the widespread enactment of child restraint laws. ${ }^{24}$ There were drops in pediatric motor vehicle related mortality of approximately $30 \%-40 \%$ in the states encompassing the Navajo Nation over the same time period (CDC WISQARS database). It is possible that the drop in motor vehicle related discharges for Navajo children reflects these national and regional secular trends. Furthermore, given the national and regional trends toward a decrease in mortality it is unlikely that the drop in discharge rates resulted from increased crash site mortality. We also were unable to measure the proportion of children transferred off reservation lands and out of the Navajo IHS for care. Children flown from the scene of a crash or transferred from an IHS facility for tertiary trauma care are likely to represent a more severely injured subset of children. However, there is no reason to believe that the capability of the IHS medical system to ventilate and medically or surgically manage a severely injured child changed significantly before or after the 1988 laws. Therefore, transfer out of the Navajo IHS is unlikely to represent a systematic error in case ascertainment. We also were unable to measure exposure to the road traffic environment with this dataset.

\section{Conclusions}

This study demonstrates a reduction in hospital discharge rates for pediatric motor vehicle injuries after the implementation of a child occupant restraint law and seat belt law in the Navajo Nation. The severity of injury to very young Navajo children was significantly reduced after enactment and

\section{Key points}

- This study demonstrates a reduction in hospital discharge rates for pediatric motor vehicle injuries after the implementation of primary enforcement child occupant restraint law and seat belt law in the Navajo Nation.

- The proportion of children discharged with more severe injuries (NISS >4) significantly decreased for Navajo children less than 5 years of age after enactment and enforcement of the 1988 child restraint laws.

- The beneficial effects of child occupant restraint legislation shown in Navajo children in this study may be replicable in other Native American tribes currently lacking such laws.

enforcement of this law. The magnitude of effect of the restraint laws on pediatric motor vehicle injuries was shown to be greater than previously reported for all Navajos ( $50 \%$ v $28 \%$ reduction).

\section{IMPLICATIONS FOR PREVENTION}

This legislative effort on the part of the Navajo Nation may serve as an example to other US Native American tribes of the effectiveness of a primary enforcement child restraint law. The 1988 Navajo child occupant restraint law and seat belt laws, at the time of their passage, represented some of the earliest, comprehensive primary enforcement laws covering most Navajo children riding in automobiles. Significant gaps in coverage for child occupant restraint across the US have not, to date, been rectified. ${ }^{37}$ In addition, many tribes have not to date enacted occupant protection laws or do not aggressively enforce the ones currently in place. Passage and enforcement of occupant restraint laws continues to be a pressing issue for Native American children in order to narrow the mortality and morbidity disparity with other American children.

\section{ACKNOWLEDGEMENTS}

Dr Phelan was supported by a National Research Service Award (HRSA PE 10027). Presented at May, 2002 APA/PAS meetings in Baltimore, $\mathrm{MD}$.

\section{Authors' affiliations}

K J Phelan, J Khoury, H Kalkwarf, Divisions of Health Policy and Clinical Effectiveness and General and Community Pediatrics, Children's Hospital Medical Center, Cincinnati, Ohio

D C Grossman, Harborview Injury Prevention and Research Center, Department of Pediatrics, University of Washington, Seattle, Washington D Hu, Tuba City Indian Medical Center, Navajo Area Indian Health Service, Tuba City, Arizona

L J D Wallace, National Center for Injury Prevention and Control, Centers for Disease Control, Atlanta, Georgia

N Bill, Navajo Area Indian Health Service, Office of Environmental Health and Injury Prevention Program, Window Rock, Arizona

\section{REFERENCES}

1 Anderson R, Kochanek K, Murphy S. Report of final mortality statistics, 1995. Monthly Vital Statistics Report. Hyattsville, MD: National Center for Health Statistics, 1997: 23

2 Rivara FP, Grosman DC. Prevention of traumatic deaths to children in the United States: how far have we come and where do we need to go? Pediatrics 1996:97:791-7.

3 Rivara FP. Pediatric injury control in 1999: where do we go from here? Pediatrics 1999;103:883-8.

4 Agran P, Winn, D, Anderson C. Child occupant protection in motor vehicles. Pediatrics in Review 1997:18:413-22.

5 9th Circuit Court DFn. Confederated Tribes of the Colville Reservation v State of Washington. Denver: 112th S Ct 1704 (1992), 1991.

6 Baker S, Whiffield R, O'Neil B. Geographic variations in mortality from motor vehicle crashes. N Engl J Med 1987;316:1384-7.

7 Shalala DE, Trujillo MH, Hartz GJ, et al Regional differences in Indian health. Rockville, MD: US DHHS, Indian Health Service, 2000: 63.

8 Grossman DC, Sugarman J, Fox C, et al. Motor-vehicle crash-injury risk factors among American Indians. Accid Anal Prev 1997;29:313-19.

9 Osberg J, Di Scala C. Morbidity among pediatric motor vehicle crash victims: the effectiveness of seat belts. Am J Public Health 1992;82:422-5 
10 Shalala D, Trujillo M, Hartz G, et al. Trends in Indian health, 1997 Rockville, MD: Indian Health Service, US Department of Health and Human Services, 1998: 214.

11 Shalala DE, Trujillo MH, Harry RH, et al. Regional differences in Indian health, 1997. Rockville, MD: Indian Health Service, Division of Program Statistics, 1997: 61.

12 Bill N, Buonviri G, Bohan P, et al. Safety-belt use and motor-vehicle-related injuries-Navajo Nation, 1988-1991. MMWR Morb Mortal Wkly Rep 1992;41(38):705-8.

13 Smith S, Colwell L, Sniezek J. An evaluation of external cause-of-injury codes using hospital records from the Indian Health Service. Am J Public Health 1990;80:279-81.

14 D'Angelo T, Handler A, Kaufman S. Is it service population or user population? The IHS Primary Care Provider 1993;18(9):153-6.

15 ICDMAP-90 (program). Bel Air, MD, 1998.

16 MacKenzie E. Classifying trauma severity based on hospital discharge diagnoses-validation of an ICD-9CM to AIS-85 conversion table. Med Care 1989;27:412-22.

17 MacKenzie E, Morris J, Smith G, et al. Acute hospital costs of trauma in the United States: implications for regionalized systems of care. J Trauma 1990;30:1096-103

18 Durbin D, Localio A, MacKenzie E. Validation of the ICD/AIS MAP for pediatric use. Inj Prev 2001;7:96-9.

19 Stevenson M, Segui-Gomez M, Lescohier I, et al. An overview of the injury severity score and the new injury severity score. Inj Prev $2001 ; 7: 10-13$

20 Phelan K, Khoury J, Kalkwarf H, et al. Trends and patterns of playground injuries in United States children and adolescents. Ambulatory Pediatrics 2001;1(July-August):227-33.

21 Macarthur C, Hu X, Wesson D, et al. Risk factors for severe injurie associated with falls from playground equipment. Accid Anal Prev 2000;32:377-82.

22 Fleiss J. Statistical methods for rates and proportions. 2nd Ed. New York: John Wiley, 1981

23 Smith R. Inventory of tribal traffic laws. Rockville, MD: Indian Health Service, 1995: 1-32.
24 Bull M, Sheese J. Update for the pediatrician on child passenger safety: five principles for safer travel. Pediatrics 2000;106:1113-16.

25 NCIPC, Division of Unintentional Injury Prevention, Atlanta, CDC. Motor-vehicle occupant fatalities and restraint use among children aged 4-8 years-United States, 1994-1998. MMWR Morb Mortal Wkly Rep 2000: 135-7.

26 Agran P. Pediatric injuries in the back of pickup trucks. JAMA 1990;264:712-16

27 Anderson C, Agran P, Winn D, et al. Fatalities to occupants of cargo areas of pickup trucks. Accid Anal Prev 2000:32:533-40.

28 Williams A, Wells JK, Lund AK. Shoulder belt use in four states with belt use laws. Accid Anal Prev 1987;19:251-60.

29 Pace B, Thailer R, Kwiatkowski T. New York State mandatory seatbelt use law: patterns of seatbelt use before and after legislation. J Trauma 1986;20:1031-3.

30 Margolis L, Broken J, Stewart J. Effects of North Carolina's mandatory safety belt law on children. Inj Prev 1996;2:32-5.

31 Rivara FP, Thompson D, Cummings P. Effectiveness of primary and secondary enforced seat belt laws. Am J Prev Med 1999;16(1S):30-9.

2 Wagenaar A, Webster D. Preventing injuries to children through compulsory automobile safety seat use. Pediatrics 1986;78:662-72.

33 Agran P, Dunkle D, Winn D. Effects of legislation on motor vehicle injuries to children. Am J Dis Child 1987;141:959-64.

34 Scheidler M, Shultz B, Schall L, et al. Risk factors and predictors of mortality in children after ejection from motor vehicle crashes. J Trauma 2000;49:864-8

35 Quinlan K, Wallace LD, Furner SE, et al. Motor vehicle related injuries among American Indian and Alaskan Native youth, 1981-1992: analysis of a national hospital discharge data base. Inj Prev 1998:4:276-9.

36 Morgenstern H. Ecologic studies in epidemiology: concepts, principles, and methods. Annu Rev Public Health 1995;16:61-81

37 Insurance Institute for Highway Safety, Arlington, VA. Child restraint laws. Insurance Institute for Highway Safety, 2001 (http:// www.highwaysafety.org/safety.org/safety_facts/state_laws/ restrain.htm).

\section{BOARD MEMBER BIOGRAPHY}

\section{Richard J Waxweiler, PhD, MSIE}

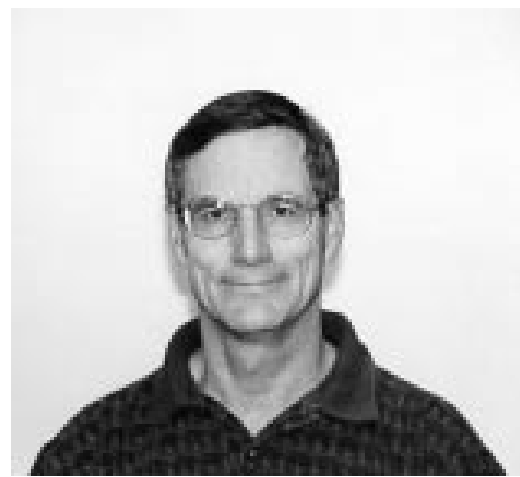

D

Waxweiler received his bachelor's and master's degrees in engineering from the University of Michigan and a doctorate in epidemiology from the University of North Carolina. His career at the Centers for Disease Control and Prevention (CDC) began in 1971 as an epidemiologist/industrial hygienist at the National Institute for Occupational Safety and Health (NIOSH) where he led a research staff that focused on the identification and control of occupational carcinogens. Afterwards, he investigated radiation related health effects while at the Los Alamos National Laboratory and toxic waste site health effects for the National Center for Environmental Health at CDC. He joined the injury control program at CDC in 1985, where he first directed the Epidemiology Branch. As Special Assistant for Scientific Affairs for the injury program, he led the development of the National Agenda and National Plan for Injury Control. He has been active in the American Public Health Association where he has served as Chairman of the Injury Control and Emergency Health Services Section, and in the Association of Georgia as a board member. He served as the Director, Division of Acute Care, Rehabilitation Research, and Disability Prevention Division which focuses on acute care and rehabilitation of injured persons and prevention of related disabilities and secondary conditions. He also served as the Acting Deputy Director of the National Center for Injury Prevention and Control. Currently, he is serving as the Associate Director for Extramural Research. 